\title{
The immigrant effect: factors impacting use of primary and emergency department care - a Canadian population cross-sectional study
}

\author{
Robert Ohle, MB, Bch, BAO, MA, MSc*; Helena Bleeker, BScH, MBT ${ }^{\dagger}$; Krishan Yadav, MD, MSc*; \\ Jeffrey J. Perry, MD, MSc*
}

\section{ABSTRACT}

Objective: In 2011, Canada had a foreign-born population of approximately $6,775,800$. They represented $20.6 \%$ of the total population. Immigrants possess characteristics that reduce the use of primary care. This is thought to be, in part, due to a lower education level, employment, and better health status. Our objective was to assess whether, in an immigrant population without a primary care physician, similar socioeconomic factors would also reduce the likelihood of using the emergency department compared to a non-immigrant population without primary care.

Methods: Data regarding individuals $\geq 12$ years of age from the Canadian Community Health Survey from 2007 to 2008 were analysed ( $n=134,073$; response rate $93 \%$ ). Our study population comprised 15,554 individuals identified without a primary care physician who had a regular place for medical care. The primary outcome was emergency department as a regular care access point. Socioeconomic variables included employment, health status, and education. Covariates included chronic health conditions, mobility, gender, age, and mental health. Weighted logistic regression models were constructed to evaluate the importance of individual risk factors.

Results: The sample of 15,554 (immigrants $n=1,767$ ) consisted of $57.3 \%$ male and $42.7 \%$ female respondents from across Canada. Immigrants were less likely than Canadianborn respondents to use the emergency department as a regular access point for health care (odds ratio $=0.48[95 \% \mathrm{Cl}$ $0.40-0.57]$ ). Adjusting for health, education, or employment had no effect on this reduced tendency (odds ratio $=$ 0.47 [95\% Cl $0.38-0.58]$ ).

Conclusion: In a Canadian population without a primary care physician, immigrants are less likely to use the emergency department as a primary access point for care than Canadianborn respondents. However, this effect is independent of previously reported social and economic factors that impact use of primary care. Immigration status is an important but complex component of racial and ethnic disparity in the use of health care in Canada.

\section{RÉSUMÉ}

Introduction: La population née à l'étranger s'élevait à environ 6775800 personnes au Canada, en 2011, soit à 20,6 \% de la population totale. Les immigrants ont des caractéristiques telles qu'ils utilisent moins les soins primaires que les Canadiens et Canadiennes de naissance. Cela s'expliquerait en partie par le niveau moins élevé de scolarité, l'emploi et un meilleur état de santé. L'étude visait donc à évaluer si, dans une population d'immigrants non suivis par des médecins de premiers recours, des facteurs socioéconomiques similaires auraient également pour effet de réduire les probabilités d'utilisation des soins d'urgence, comparativement à une population de nonimmigrants aussi dépourvus de médecins de premier recours. Méthode: Ont été analysées des données provenant de I'Enquête sur la santé dans les collectivités canadiennes de 2007-2008, et concernant des personnes âgées de 12 ans et plus ( $n=134$ 073; taux de réponse : $93 \%$ ). La population à l'étude comptait 15554 personnes non suivies par un médecin de premier recours mais se rendant dans des points de services habituels pour obtenir des soins médicaux. Le principal critère d'évaluation consistait en l'utilisation des services des urgences (SU) comme porte d'entrée du système de soins de santé. Les variables socioéconomiques comprenaient l'emploi, l'état de santé et le niveau de scolarité; et les covariables, les maladies chroniques, la mobilité, le sexe, l'âge et l'état de santé mentale. Les chercheurs ont élaboré des modèles de régression logistique pondérée afin d'évaluer l'importance de différents facteurs de risque considérés individuellement.

Résultats: L'échantillon comptait 15554 personnes (immigrants $n=1,767$ ) provenant de toutes les régions du Canada, dont $57,3 \%$ d'hommes et $42,7 \%$ de femmes. Les immigrants étaient moins susceptibles d'utiliser les SU comme porte d'entrée principale du système de soins de santé que les répondants nés au Canada (risque relatif approché $[\mathrm{RRA}]=0,48$ [IC à $95 \%: 0,40-0,57]$ ). Le rajustement des valeurs pour tenir compte de l'état de santé, du niveau de scolarité et de l'emploi n'a eu aucune incidence sur cette tendance à la baisse (RRA $=0,47$ [IC à $95 \%: 0,38-0,58]$ ).

From the *Department of Emergency Medicine, School of Epidemiology, Population Health and Preventative Medicine, University of Ottawa, The Ottawa Hospital Research Institute, Ottawa, ON; and the ${ }^{\dagger}$ Undergraduate Department of Medicine, University of Ottawa, Ottawa, ON.

Correspondence to: Robert Ohle, The Ottawa Hospital Research Institute, The Ottawa Hospital, Civic Campus, 1053 Carling Avenue, Ottawa, ON K1Y 4E9; Email: robert.ohle@gmail.com 
Conclusions: Si l'on considère l'ensemble de la population dépourvu de médecins de premier recours au Canada, les immigrants sont moins susceptibles d'utiliser les SU comme porte d'entrée principale du système de soins de santé que les Canadiens et Canadiennes de naissance. Toutefois, cet effet est indépendant des facteurs sociaux et économiques reconnus antérieurement comme ayant une incidence sur I'utilisation des soins primaires. Le statut d'immigrant constitue un facteur important mais complexe de disparité raciale et ethnique dans l'utilisation des soins de santé au Canada.

Keywords: emergency department, immigrant, primary care

\section{INTRODUCTION}

In 2011, Canada had a foreign-born population of approximately $6,775,800$. They represented $20.6 \%$ of the total population, the highest proportion amongst the G8 countries. With an annual influx of $240,000,{ }^{1}$ this cohort is expected to continue to grow. Lower socioeconomic status (SES), ${ }^{2-5}$ immigrant health, and unemployment all reduce primary care use. ${ }^{6}$ Immigrants are defined as an at-risk population due to their unique characteristics that reduce their use of primary care. ${ }^{7-9}$

Data regarding immigrants' tendency to access emergency health care are conflicting. Several studies have found increased emergency department use among immigrant populations, ${ }^{10-14}$ whereas others have found decreased use. ${ }^{15-18}$ Across the general population, a lack of primary care physician seems to increase the likelihood of emergency department use. ${ }^{13}$

The lack of health care use has been correlated with poor health outcomes. ${ }^{19}$ Given the already lower SES among immigrant populations in Canada, ${ }^{20-22}$ it is important to understand the factors that impact both primary and emergency department care use in this group in order to guide the adaptation of our health care system to accommodate these factors and thus ensure equitable health care use.

The objective of this paper was to assess whether immigrants lacking primary care would demonstrate reduced likelihood of using the emergency department as a regular care access point compared to Canadian-born patients similarly lacking primary care. Our secondary objective was to assess whether commonly reported factors reducing use of primary care would impact the emergency department tendencies studied here.

\section{METHODS}

\section{Study population}

The analyses for this study were based on data from the 2007-2008 Canadian Community Health Survey
(CCHS). This is a cross-sectional survey collecting information from those ages 12 years and older living in private dwellings in Canada. Excluded from the study population were individuals who lived on First Nations reserves or crown lands, full-time members of the Canadian Armed Forces, people in institutions, homeless people, and people living in remote regions. The CCHS covers approximately $98 \%$ of the Canadian population ages 12 and over.

A multistage, stratified sampling design was used, with each dwelling as the final sampling unit. Demographic data were obtained for 144,836 households, and one or two people per household were asked to complete an in-depth interview. From this sample, 134,073 individual responses were obtained, giving a national response rate of $93 \%$. The survey included questions related to health status, health care use, and health determinants.

From the survey database, we identified people who reported having no primary care physician $(\mathrm{n}=15,554)$. We did not use any age or province restrictions. In the health care utilization module, respondents were asked whether they had a primary care physician; if they said no, they were asked whether they had a regular place that they attended for care. If they answered yes, they were asked where this place was, and those responding to this question defined our study population.

\section{Exposure and outcome variables}

Our outcome variable was defined as use of the emergency department as the primary access point for health care. We dichotomized the possible answers to the CCHS question, "Where is your usual place for health care?" into emergency department versus other. Exposure variables were education, self-reported health status, and employment. Covariates were previously reported factors that altered emergency department use: age, region, income, chronic disease, gender, selfreported mental heath status, and difficulty attending medical appointments (defined as a mobility issue). 
Education was dichotomized into those with an education above or below the secondary school level. Income was dichotomized into above or below $\$ 20,000$. Health status and mental health status were both selfreported on a scale of 1 to 5 ; these were collapsed into poor $(<3)$ or good health. ${ }^{3-5}$ Employment status was dichotomized into employed and unemployed. Age was collapsed into four categories: $<18 ; 18-45 ; 46-65$; and $>65$. Immigrant status was self-reported as yes or no. Chronic disease was a composite variable, and yes was defined as any respondent reporting a history of asthma, arthritis, mood or anxiety disorder, diabetes, heart disease, emphysema, chronic obstructive pulmonary disease, or chronic bronchitis. For the mobility issue covariate, yes was defined as difficulty attending a medical appointment.

\section{Statistical analysis}

Prevalence estimates and 95\% confidence intervals (CIs) for each variable were calculated. Weighted logistic regression models were constructed to evaluate the importance of individual risk factors and their interactions after adjustment for relevant covariates. Model parameters were estimated by the method of maximum likelihood, and the Wald statistic was used to test the significance of individual variables or interaction terms in relation to emergency department choice. To model the effect of covariates and independent variable (immigrant status) on the emergency department as a regular place to seek care, we constructed a model with regular place of care as the dependent variable. To describe the variation in impact of covariates on describing the emergency department as a regular point of access for care, we split our sample into immigrant and non-immigrant populations and then analysed our model with covariates now as independent variables and immigrant status not included.

The CCHS 2007-2008 data were based on a complex survey design incorporating stratification, multiple stages of selection, and unequal probabilities of selection for respondents. Therefore, standard statistical methods may not be appropriate for the analysis of these data. The CCHS microdata documentation provides guidelines stating that population sample weights (expansion weights) must be used to produce correct population estimates. This weighting takes into account the patterns of missing data and the oversampling of some strata. The CCHS 2007-2008 public release data file provides these population weights. In our models, records that contained missing data for any of the explanatory covariates were deleted if they compromised greater than $10 \%$ of the available data.

\section{RESULTS}

The study population included 15,554 survey respondents (immigrants $\mathrm{n}=1,767$ ) from across Canada who did not have a primary care physician but did have a regular place to go for health care. The emergency department was the primary access point for 2,750 (18.7\%) respondents, a weighted representation of 456,656 Canadian residents. The sample comprised $57.3 \%$ males. The response rates across individual provinces varied from $78.5 \%$ to $87.0 \%$. In our study, immigrants without a primary care provider were less likely to report that they use the emergency department as a regular point of care access than Canadian-born respondents similarly lacking primary care (odds ratio $[\mathrm{OR}]=0.48$ [95\% CI $0.40-0.57])$. Adjusting for health, education, or employment had no effect on this reduced access (OR $=0.47$ [95\% CI $0.38-0.58]$ ) (Tables 1-4; Figure 1). The presence of a chronic condition, greater age, less than secondary school education, and male respondents had an increased use of the emergency department in a non-immigrant population but had no effect in an immigrant population. Income was not used in our model because $>20 \%$ of data was missing.

\section{STRENGTHS AND LIMITATIONS}

Our study has several limitations. One important limitation is that all of the data collected were self-reported and thus subject to recall bias - namely, the selfreported tendency for emergency departments as a regular point of health care access because it was our primary outcome. The variable education was collapsed into two categories. This could potentially lead to misclassification bias; however, in analysing the maximum likelihood test, the larger number of categories did not add significantly to the model. The CCHS is from 2008, and thus trends may have since shifted. Finally, unmeasured variables that may have impacted emergency department use (health literacy, cultural preferences, and language) were not reported in the CCHS data and therefore could not be controlled for in the regression analysis. 


\begin{tabular}{|c|c|c|c|c|}
\hline \multirow[b]{2}{*}{ Characteristics } & \multirow[b]{2}{*}{ Total } & \multicolumn{2}{|c|}{$\mathrm{N}(\%)$} & \\
\hline & & Immigrants & Non-immigrants & \\
\hline Emergency department as primary access & $2750(18.7)$ & $203(12.2)$ & $2473(20)$ & $p<0.001$ \\
\hline Income & $7889(64)$ & $911(64.7)$ & $6808(63.9)$ & $p<0.5$ \\
\hline Chronic conditions & 791 (39.4) & $588(35.4)$ & $5090(40.1)$ & $p<0.001$ \\
\hline \multicolumn{5}{|l|}{ Age } \\
\hline $0-17$ & & $78(4.7)$ & $1153(9.1)$ & $p<0.001$ \\
\hline $18-44$ & & $1022(61.2)$ & $7063(55.6)$ & \\
\hline $45-64$ & & $397(23.8)$ & $3425(27)$ & \\
\hline 65-100 & & $174(10.4)$ & $1057(8.3)$ & \\
\hline \multicolumn{5}{|l|}{ Regions } \\
\hline Ontario \& Quebec & $7415(50.5)$ & $1005(60.1)$ & $6215(48.9)$ & $p<0.001$ \\
\hline Western Canada & $46303(1.5)$ & $562(33.6)$ & 3971 (31.3) & \\
\hline Northern territories & $1207(8.2)$ & $37(2.2)$ & $1144(9)$ & \\
\hline Maritimes & $1442(9.8)$ & $67(4)$ & $1368(10.8)$ & \\
\hline Employed & $11069(82.2)$ & $1192(78.1)$ & $9640(82.8)$ & $P<0.001$ \\
\hline Good health & $13256(90.3)$ & $1517(90.1)$ & $11448(90.2)$ & $P<0.4$ \\
\hline Good mental health & $12659(94.5)$ & $1538(94.6)$ & $11824(94.5)$ & $P<0.9$ \\
\hline Difficulty attending appointments & $508(3.5)$ & $51(3)$ & $445(3.5)$ & $P<0.3$ \\
\hline Education > secondary level & & 1445 (93.5) & $10218(86.9)$ & $P<0.001$ \\
\hline Male & 8378 (57.) & $939(56.2)$ & $7257(57.2)$ & $P<0.5$ \\
\hline
\end{tabular}

\begin{tabular}{|c|c|c|}
\hline \multirow[b]{2}{*}{ Characteristics } & \multicolumn{2}{|c|}{ OR $(95 \% \mathrm{Cl})$} \\
\hline & Immigrants & Non-immigrants \\
\hline Chronic conditions & $0.81(0.57-1.2)$ & $1.1(1-1.2)^{*}$ \\
\hline Age & $1.2(0.96-1.58)$ & $1.1(1.01-1.2)^{*}$ \\
\hline Regions & $0.93(0.75-1.2)$ & $0.62(0.59-0.66)^{*}$ \\
\hline Employed & $0.75(0.51-1.1)$ & $0.9(0.78-1)$ \\
\hline Good health & $0.79(0.44-1.4)$ & $0.84(0.70-1)$ \\
\hline Good mental health & $0.88(0.44-1.8)$ & $1.1(0.91-1.4)$ \\
\hline $\begin{array}{l}\text { Difficulty attending } \\
\text { appointments }\end{array}$ & $1.8(0.76-4.3)$ & $0.94(0.68-1.3)$ \\
\hline $\begin{array}{l}\text { Education > secondary } \\
\text { level }\end{array}$ & $0.67(0.38-1.2)$ & $0.73(0.62-0.84)^{*}$ \\
\hline Male & $1.1(0.79-1.5)$ & $1.5(1.3-1.6)^{*}$ \\
\hline
\end{tabular}

Strengths of our study include a large sample size giving us power to detect smaller effects. Our sampling error is reduced with our large sampling size with a complex survey and a high response rate. Our results are also generalizable across Canada given that our source data were a national survey.

\begin{tabular}{|c|c|c|}
\hline \multirow[b]{2}{*}{ Characteristics } & \multicolumn{2}{|c|}{ OR $(95 \% \mathrm{Cl})$} \\
\hline & Unadjusted & Adjusted \\
\hline Immigrant & $0.48(0.40-0.57)$ & $0.47(0.38-0.58)$ \\
\hline Employed & - & $0.86(0.75-0.99)$ \\
\hline Good health & - & $0.84(0.7-1)$ \\
\hline Education > secondary level & - & $0.72(0.62-0.84)$ \\
\hline Chronic conditions & $1.1(1-1.2)$ & $1.1(0.99-1.2)$ \\
\hline Age & $1.1(1-1.1)$ & $1.1(1-1.2)$ \\
\hline Regions & $0.63(0.6-0.67)$ & $0.63(0.6-0.67)$ \\
\hline Good mental health & $0.99(0.81-1.2)$ & $1(0.89-1.4)$ \\
\hline $\begin{array}{l}\text { Difficulty attending } \\
\text { appointments }\end{array}$ & $1.4(1.1-1.7)$ & $1.4(1.1-1.7)$ \\
\hline Male & $1.4(1.3-1.5)$ & $1.4(1.3-1.5)$ \\
\hline
\end{tabular}

\section{DISCUSSION}

The 1984 Canada Health Act (CHA) sets out the primary objective of health care: "to protect, promote, and restore the physical and mental well-being of residents of Canada and to facilitate reasonable 


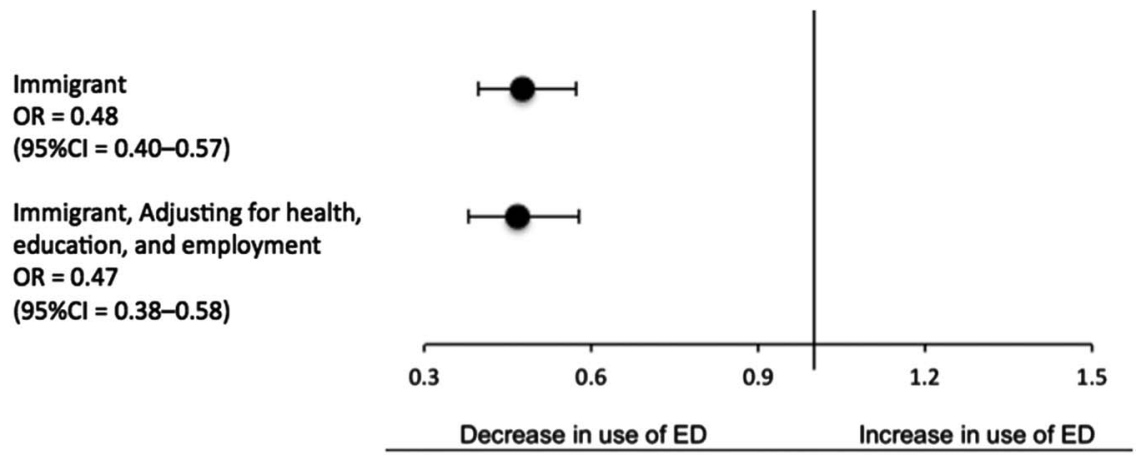

Figure 1. Unadjusted and adjusted odds of using the emergency department for regular health care (adjusting for education, employment, and health status) among an immigrant population versus a non-immigrant population.

access to health services without financial or other barriers." 23

Immigrants without a primary care physician are less likely to report the emergency department as a regular point of health care access, and thus may receive different care than non-immigrants. Previously reported factors leading to reduced use of primary care do not account for the reduced tendency to use the emergency department by an immigrant population seen in this study.

Literature on immigrant use of the emergency department is conflicting. Several studies have found increased emergency department use among immigrant populations, ${ }^{10-14}$ whereas others have found decreased use. ${ }^{15-18}$ These studies tended to define immigrants as a homogeneous population and did not take into account patient access to a primary care provider or potentially confounding factors such as SES, the healthy immigrant effect, education, and legal issues surrounding immigration.

Even after controlling for health status, education level, and employment, immigrants were less likely to report using the emergency department as the regular place they sought care. Ahmed et al. (2015) discuss cultural barriers to accessing primary care that exist outside of education and SES. ${ }^{1}$ There may also be difficulties understanding a new health care system in a different language. ${ }^{1,24,25}$ Additionally, there may be confusion or frustration with the Canadian system with respect to specialist referrals and management of patient information, which differs from the private systems in other countries. ${ }^{1,25,26}$ Furthermore, differences in cultural norms may become apparent in the context of emergency department care, such as preferred physician gender, sharing hospital rooms, discussing sensitive issues, or views of what health problems warrant seeking medical care. ${ }^{1,25}$ These factors, considered together, seem to represent features of health literacy, which would be understandably lower in those who are new to the Canadian system. As our results suggest, they may be acting independently of employment, health status, and education and impacting emergency department use among immigrants.

Another potential explanation for the reduced likelihood of emergency department use for regular care is that the immigrant population is healthier, as described by the healthy immigrant effect. ${ }^{1}$ However, this effect has been shown to be not only temporary but also reversed over time, ${ }^{1}$ and because our immigrant population was defined as foreign-born and thus not limited by the duration of time lived in Canada, the health status of recent and less-recent immigrants was likely homogeneous. As a future direction, the effect of health status on health care use would be interesting to study with narrower population definitions.

We have shown that immigrants without a primary care physician are less likely than Canadian-born individuals to regularly seek care in the emergency department. In a universally funded health system where inequalities in care delivery continue to exist, we need to further evaluate whether this reduced use equates to reduced access.

\section{CONCLUSION}

The provision of health care to an immigrant population is a complex, diverse, and ever-changing process. Canadian immigrants without a primary care physician are less likely than non-immigrants to use the emergency department as for their regular health care. Factors that impede Canadian immigrants' use of 


\begin{tabular}{|c|c|c|}
\hline \multirow[b]{2}{*}{ Regular place for health care } & \multicolumn{2}{|c|}{$\%$} \\
\hline & Immigrant & Non-immigrant \\
\hline Doctors office & 5.2 & 5.4 \\
\hline Community health centre & 8.6 & 14.7 \\
\hline Walk-in clinic & 59.3 & 41.6 \\
\hline Appointment clinic & 6 & 7.7 \\
\hline Telephone health line & 0.9 & 1 \\
\hline Emergency department & 12.2 & 20 \\
\hline Hospital outpatient clinic & 2.6 & 4.7 \\
\hline Other & 5.2 & 4.9 \\
\hline
\end{tabular}

primary care do not adequately account for this decreased tendency. With an ever increasing number of immigrants becoming new Canadians, we must further elucidate the factors that impact their health care use so as to ensure that our system is as equitable as possible.

Competing interests: None declared.

\section{REFERENCES}

1. Ahmed SN, Rumana N, Barron GRS, et al. Barriers to access of primary healthcare by immigrant populations in Canada: a literature review. 7 Immigr Minor Health 2016; 18(6):1522-40.

2. Brar S, Tang S, Drummond N, et al. Perinatal care for South Asian immigrant women and women born in Canada: telephone survey of users. 7 Obstet Gynaecol Can 2009;31:708-16.

3. Reitmanova S, Gustafson DL. "They can't understand it": maternity health and care needs of immigrant Muslim women in St. John's, Newfoundland. Matern Child Health 7 2008;12:101-11.

4. Reitmanova S, Gustafson DL. Primary mental health care information and services for St. John's visible minority immigrants: gaps and opportunities. Issues Ment Health Nurs 2009;30:615-23.

5. Dunlop S, Coyte PC, McIsaac W. Socio-economic status and the utilisation of physicians' services: results from the Canadian National Population Health Survey. Soc Sci Med 2000;51:123-33.

6. McDonald JT, Kennedy S. Insights into the "healthy immigrant effect": health status and health service use of immigrants to Canada. Soc Sci Med 2004;59:1613-27.

7. Sanmartin C, Ross N. Experiencing difficulties accessing first-contact health services in Canada. Health Care Policy 2006;1(2):103-19.

8. Asanin J, Wilson K. "I spent nine years looking for a doctor": exploring access to health care among immigrants in Mississauga, Ontario, Canada. Soc Sci Med 2008;66(6): 1271-83.
9. Muggah E, Dahrouge S, Hogg W. (2012). Access to primary health care for immigrants: results of a patient survey conducted in 137 primary care practices in Ontario, Canada. BMC Fam Pract 2012;13:128.

10. Hjern A, Persson G, Roen M. Is there equity in access to health services for ethnic minorities in Sweden? Eur 7 Public Health 2001;11(2):147-52.

11. Norredam M, Sorensen TM, Keiding N, et al. Emergency room utilization in Copenhagen: a comparison of immigrant groups and Danish-born residents. Scand 7 Public Health 2004;32(1):53-9.

12. Correa-Velez I, Brown K, Gifford SM. Hospital utilization among people born in refugee-source countries: an analysis of hospital admissions, Victoria, 1998-2004. Med 7 Aust 2007;186(11):577.

13. Mian O, Pong R. Does better access to FPs decrease the likelihood of emergency department use? Can Fam Physician 2012;56:e658-66.

14. Rué M, Soler-González J, Bosch A, et al. Emergency hospital services utilization in Lleida (Spain): a cross-sectional study of immigrant and Spanish-born populations. $B M C$ Health Serv Res, 8:81.

15. Wen SW, Williams JI. Utilization of health care services by immigrants and other ethnic/cultural groups in Ontario. Ethnic Health 1996;1(1):99-109.

16. $\mathrm{Ku} \mathrm{L}$. Left out: immigrants' access to health care and insurance. Health Affair 2001;20(1):247-56.

17. Cunningham PJ. What accounts for differences in the use of hospital emergency departments across US communities? Health Affair 2006;25(5):w324-36.

18. Buron A, Garcia O, Vall O, et al. Hospital emergency department utilization rates among the immigrant population in Barcelona, Spain. BMC Health Serv Res 2008;8(51):1-10.

19. Wu Z, Penning MJ, Schimmele CM. Immigrant status and unmet health care needs. Can $\mathcal{F}$ Public Health 2005;96:369-73.

20. Dunn JR, Dyck I. Social determinants of health in Canada's immigrant population: results from the national population health survey. Soc Sci Med 2000;51:1573-93.

21. Laroche M. Health status and health services utilization of Canada's immigrant and non-immigrant populations. Can Public Policy 2000;26:51-75.

22. Ng E, Wilkins R, Gendron F, et al. Dynamics of immigrants health in Canada: evidence from the National Population Health Survey. In Healthy today, bealthy tomorrow? Findings from the National Population Health Survey. Statistics Canada, Catalogue 82-618. Ottawa: Statistics Canada; 2005.

23. Canada S. Canadian Community Health Survey, 2012: Annual component [public-use microdata file]. Ottawa: Statistics Canada, Health Statistics Division, Data Liberation Initiative; 2013.

24. Fiscella KFP, Doescher MP, Saver BG. Disparities in health care by race, ethnicity, and language among the insured: findings from a national sample. Med Care 2002;40(1):52-9.

25. $\mathrm{Ng} \mathrm{C}$. Health care providers' perspectives on the provision of prenatal care to immigrants. Cult Health Sex 2011; 13(5):561-74.

26. Liu R, Quan H. Chinese and white Canadian satisfaction and compliance with physicians. BioMed Central 2007;21(8):11. 